\title{
SUPLEMENTAÇÃO COM AMÊNDOA DE BACURI NA COMPOSIÇÃO CORPORAL DE RATOS SUBMETIDOS AO EXERCÍCIO
}

Artigo Original

Original ARticle Artículo Original

\author{
SUPPLEMENTATION WITH BACURI ALMOND IN THE BODY COMPOSITION OF RATS \\ SUBMITTEDTOTHEEXERCISE
}

SUPLEMENTACIÓN DE ALMENDRA DEL BACURIEN LA COMPOSICIÓN CORPORAL DE RATAS

SOMETIDAS A EJERCICIO

Marília de Lima Mendes Ramos' (Nutricionista)

Gabrielly da Costa Gomes Rodrigues' (Graduanda em Nutrição) Willian Rafael Gonçalves Soares? (Nutricionista)

Priscila Aiko Hiane' (Farmacêutica) Maria Isabel Lima Ramos' (Farmacêutica)

Jeeser Alves de Almeida' (Profissional de Educação Física) Fabiane La Flor Ziegler Sanches' (Nutricionista/Farmacêutica)

1. Programa de Pós Graduação em Saúde e Desenvolvimento na Região Centro Oeste - PPGSD. Universidade Federal de Mato Grosso do Sul (UFMS),

Campo Grande, MS, Brasil.

\section{Correspondência:}

Fabiane La Flor Ziegler Sanches Universidade Federal de Mato Grosso do Sul (UFMS), Faculdade de Ciências Farmacêuticas, Alimentos e Nutrição (FACFAN), Curso de Nutrição, Cidade Universitária, s/n. Campo Grande, MS, Brasil. 79070-900.

fabianelaflor@gmail.com

\section{RESUMO}

Introdução: A proteína da amêndoa do bacuri (Attalea phalerata Mart. Ex Spreng) e da whey protein (WP) têm quantidades relevantes de aminoácidos essenciais e são de boa digestibilidade, características que têm sido buscadas por atletas para auxílio para melhorar a composição corporal, particularmente quando associadas a exercícios. Objetivo: Avaliar o efeito de dietas com teor proteico vegetal e animal sobre a composição corporal de ratos Wistar submetidos ao exercício resistido em escada. Métodos: Quarenta ratos machos recém-desmamados foram submetidos a um período de adaptação com dieta comercial (4 semanas) e treinamento resistido durante oito semanas (três vezes por semana), recebendo dietas com farinha de bacuri e whey protein. Foram distribuídos randomicamente em seis grupos: G1 (bacuri sedentário), G2 (bacuri exercitado), G3 (WP sedentário), G4 (WP exercitado), G5 (controle sedentário) e G6 (controle exercitado). Avaliou-se consumo da dieta, peso corporal, comprimento, circunferências torácica e abdominal para calcular o índice de Lee e o índice de massa corporal; os sítios com gordura foram retirados após eutanásia. A análise estatística foi realizada por ANOVA e Teste de Tukey, considerando 5\% de significância. Resultados: O peso final do G3 (372 $\pm 8,86 \mathrm{~g})$ foi superior ao do $\mathrm{G} 2(326,83 \pm 15,03 \mathrm{~g})$ e do $\mathrm{G} 6(316,75 \pm 5,90 \mathrm{~g})$; os grupos que receberam dieta com farinha de bacuri consumiram quantidade superior de dieta, porém, tiveram menor peso final; não diferiram no índice de Lee e no IMC, sítios com gordura e índice de adiposidade com relação aos grupos tratados com WP, apresentando valores inferiores das circunferências torácica e abdominal. Com relação às gorduras e índice de adiposidade, não houve diferença entre os grupos sedentários e exercitados. Conclusão: A proteína da amêndoa de bacuri mostrou-se de boa qualidade quando comparada com a whey protein, havendo possibilidade de recomendação de seu uso na elaboração de suplementos nutricionais, como fonte vegetal alternativa e de baixo custo.

Descritores: proteínas; frutos; composição corporal; exercício.

\section{ABSTRACT}

Introduction: The bacurialmond protein (Attalea phalerata Mart. Ex Spreng) and whey protein (WP) have significant amounts of essential amino acids and are of good digestibility, characteristics that have been sought by athletes to aid in improving body composition, particularly when associated with exercises. Objective: To evaluate the effect of diets with vegetable and animal protein content on the body composition of Wistar rats submitted to resisted ladder exercise. Methods: Forty male newly weaned rats were exposed to a period of adaptation to a commercial diet (4 weeks) and resistance training for eight weeks (three times a week), receiving diets with bacuri flour and whey protein. They were randomly assigned to 6 groups: G1 (sedentary bacuri), G2 (exercised bacuri), G3 (sedentary WP), G4 (exercised WP), G5 (sedentary control) and G6 (exercised control). Dietary intake, body weight, length, thoracic and abdominal circumferences were evaluated to calculate Lee index and body mass index; the fat sites were removed after euthanasia. Statistical analysis was performed by ANOVA and Tukey's test, considering a 5\% significance level. Results: The final weight of G3 (372 $\pm 8.86 \mathrm{~g})$ was higher than those of $G 2(326.83 \pm 15.03 \mathrm{~g})$ and $\mathrm{G} 6(316.75 \pm 5.90 \mathrm{~g})$; the groups that received diet with bacuri flour consumed higher amount of food, however, they had lower final weight, did not differ in the Lee index and BMI, fat sites and adiposity index in relation to the groups treated with WP, presenting lower values in the thoracic and abdominal circumferences. Regarding fat and adiposity index, there was no difference between the sedentary and exercised groups. Conclusion: The bacuri almond protein showed good quality when compared to whey protein, and it is possible to recommend its use in the preparation of nutritional supplements as an alternative and low cost vegetable protein source.

Keywords: proteins; fruit; body composition; exercise.

\section{RESUMEN}

Introducción: La proteína de la almendra del bacuri (Attalea phalerata Mart ex Spreng) y proteína del suero de la leche (whey protein - WP) tienen cantidades significativas de aminoácidos esenciales y son de buena digestibilidad, 
características que han sido buscadas por atletas para ayudar a mejorar de la composición corporal, especialmente cuando se asocian a ejercicios. Objetivo: Evaluar el efecto de dietas con contenido proteico vegetal y animal sobre la composición corporal de ratas Wistar sometidas al ejercicio resistido en escalera. Métodos: Cuarenta ratas machos recién destetadas se sometieron a un periodo de adaptación con dieta comercial (4 semanas) y entrenamiento de resistencia durante ocho semanas (tres veces por semana), recibiendo dietas con harina de bacuri y proteína del suero de la leche. Se distribuyeron aleatoriamente en 6 grupos: G1 (bacuri sedentario), G2 (bacuri ejercitado), G3 (WP sedentario), G4 (WP ejercitado), G5 (control sedentario) y G6 (control ejercitado). Se evaluó consumo de la dieta, peso corporal, longitud, circunferencias torácica y abdominal para calcular el indice de Lee y el índice de masa corporal; los sitios con grasa se retiraron después de la eutanasia. El análisis estadístico se realizó por ANOVA y prueba de Tukey, considerando el 5\% de significación. Resultados: El peso final del G3 (372 $\pm 8,86 \mathrm{~g})$ fue superior al del G2 (326,83 $\pm 15,03$ g) y del G6 (316,75 $\pm 5,90$ g); los grupos que recibieron dieta con harina de bacuri consumieron una cantidad mayor de alimentos, sin embargo, tuvieron menor peso final; no difirieron en el índice de Lee y en el IMC, sitios con grasay indice de adiposidad con relación a los grupos tratados con WP, presentando valores inferiores en las circunferencias torácica y abdominal. Con respecto a las grasas e índice de adiposidad, no hubo diferencia entre los grupos sedentarios y ejercitados. Conclusión: La proteína de la almendra del bacuri se mostró de buena calidad en comparación con la proteína del suero de la leche, y existe la posibilidad de recomendar su uso en la preparación de suplementos nutricionales, como fuente de proteína vegetal alternativa e de bajo costo.

\section{Descriptores: proteínas; fruta; la composición corporal; el ejercicio.}

\section{INTRODUÇÃO}

A prática de atividade física associada a uma dieta balanceada é mais eficaz para que ocorra uma modificação corporal benéfica sendo essencial na formação, reparação e reconstituição de tecidos corporais, mantendo a integridade funcional e estrutural do organismo ${ }^{1,2}$.

Estudos vêm demonstrando que modificações dietéticas podem beneficiar atletas e praticantes de atividades físicas por influenciar no seu desempenho ${ }^{3}$. Os suplementos alimentares mais utilizados possuem como base em sua formulação as proteínas e aminoácidos, e os principais motivos de seu consumo são ganho de massa magra, perda de gordura, perda de peso, aumento da resistência, e para compensar dietas inadequadas 4 .

O treinamento resistido tem se popularizado nos últimos tempos devido sua importância na melhoria da saúde, podendo ser praticado por pessoas de diferentes faixas etárias com ou sem doenças associadas ${ }^{5}$. Em pesquisa realizada com mulheres saudáveis submetidas a treinamento resistido de força, com alto número de repetições, os autores confirmaram aumento de força muscular e melhor potencial aeróbico ${ }^{6}$. Além disso, esse tipo de exercício também auxilia na hipertrofia muscular ${ }^{7,8}$ e na diminuição da gordura corporal ${ }^{5}$.

Pesquisando a prevalência do consumo de suplementos em diversas modalidades de atividade física, observou-se que os mais consumidos são os proteicos, como por exemplo, o whey protein em função do conhecimento de que a proteína é o nutriente capaz de aumentar a massa muscular, principal objetivo entre os atletas ${ }^{8}$. Segundo Sgarbieri ${ }^{9}$, whey protein é um conjunto de proteínas do soro do leite de fácil digestão e absorção, além de possuir um perfil de aminoácidos expressivo que favorece a síntese proteica após o exercício. O perfil dos aminoácidos presentes no whey protein é muito semelhante ao encontrado no músculo esquelético, sendo assim, auxilia na hipertrofia muscular ${ }^{10}$.

A busca de fontes alternativas de nutrientes, principalmente proteínas, é necessária à medida que há um constante aumento da demanda consumidora de suplementos proteicos. Nesse sentido, a utilização da amêndoa bacuri (Attalea phalerata Mart. Ex Spreng), pertencente à família Arecaceae, amplamente distribuído em Mato Grosso do Sul e Mato Grosso, apresenta potencial por possuir grande quantidade de lipídios e de proteínas.
Conforme evidenciado em pesquisa recente, a amêndoa de bacuri apresenta bom perfil aminoacídico, comparado ao de whey protein concentrate (WPC), de whey protein isolate (WPI) e do padrão proposto para adultos da Food and Agriculture Organization e World Health Organization ${ }^{11-13}$. As quantidades de aminoácidos essenciais encontradas foram maiores que as recomendadas pela FAO/OMS, com digestibilidade melhor que os aminoácidos encontrados na soja. Avaliou-se também o valor nutricional desta proteína e sua digestibilidade in vitro, constatando que pode ser utilizada como fonte alternativa de proteína, pois não apresenta fatores antinutricionais e aminoácidos limitantes ${ }^{14}$.

Diante do exposto, o objetivo do presente trabalho foi analisar o efeito da dieta suplementada com proteína da amêndoa do bacuri e de whey protein sobre a composição corporal de ratos submetidos ao exercício físico.

\section{MATERIAIS E MÉTODOS}

Os frutos maduros de bacuri foram coletados em Campo Grande, MS, e regiões próximas, transportados aos laboratórios da Unidade de Tecnologia de Alimentos e Saúde Pública da UFMS, onde as amêndoas foram retiradas e processadas para elaboração da farinha desengordurada. O whey protein utilizado foi adquirido no comércio local após a verificação da marca mais indicada para realização do experimento, de acordo com o teor de proteínas.

A determinação de umidade foi realizada através de dessecação em estufa com temperatura a $105^{\circ} \mathrm{C}$, as cinzas determinadas por calcinação em mufla a $550^{\circ} \mathrm{C}$, as proteínas através do método micro-Kjeldahl, multiplicando o conteúdo de nitrogênio total (porcentagem) pelo fator de conversão $(6,25)$. Os lipídios foram avaliados pelo método de extração direta com éter de petróleo em aparelho Soxhlet. Todos esses procedimentos foram realizados segundo as metodologias do Instituto Adolfo Lutz ${ }^{15}$. Os carboidratos foram determinados através do método de Fehling ${ }^{16}$. As análises foram realizadas em triplicata.

\section{Protocolo experimental}

O estudo foi realizado no Biotério Central da Universidade Federal de Mato Grosso do Sul, em Campo Grande - MS. Foram utilizados quarenta ratos machos da linhagem Wistar recém-desmamados (21 dias), mantidos em caixas coletivas, sala com temperatura controlada $\left(22 \pm 1^{\circ} \mathrm{C}\right) \mathrm{e}$ ciclo de 12 horas claro e escuro invertido, com dieta e água ad libitum. 
Os animais receberam dieta comercial durante quatro semanas de adaptação para crescimento e treinamento resistido. Posteriormente, foram separados em diferentes grupos: $\mathrm{G} 1$ - Bacuri sedentário $(n=6)$, G2 - Bacuri exercitado ( $n=6), G 3$ - Whey sedentário ( $n=6), G 4$ - Whey exercitado ( $n=6), G 5$ - Dieta comercial sedentário $(n=8), G 6$ - Dieta comercial exercitado $(n=8)$

A intervenção dietética ocorreu durante oito semanas e as dietas foram preparadas segundo as especificações da AIN-93 $\mathrm{G}^{17}$, exceto pela concentração de proteína que foi mantida em 15\% (normoproteica) e a fonte proteica (farinha desengordurada de bacuri e whey, em substituição à caseína). A dieta comercial ofertada para os grupos controles era da marca Nuvital ${ }^{\circledR}$. O controle da ingestão dietética foi realizado três vezes por semana.

Ao final do treinamento, os animais foram mantidos em repouso por 48 horas após a última sessão de exercícios e eutanasiados por exsanguinação. O experimento foi submetido à Comissão de Ética no Uso de Animais/CEUA da UFMS e aprovado com o protocolo n 678/2015.

O treinamento resistido foi realizado no modelo de escalada em escada (110 cm de altura, $2 \mathrm{~cm}$ de espaço entre os degraus e 80 graus de inclinação) de acordo com Hornberger e Farrar $^{18}$. No final do período de adaptação, durante cinco dias, os animais foram submetidos à familiarização ao exercício (sessão diária, com uma carga de resistência fixada à cauda na porção proximal com fita adesiva (tubo plástico de $50 \mathrm{~mL}$ com carga correspondente a 10\% do peso corporal). pós a adaptação, os animais foram submetidos ao um teste incremental para determinação da carga máxima de carregamento de acordo com protocolo de Hornberger e Farrar ${ }^{18}$. Os animais treinaram durante oito semanas com uma frequência de três vezes por semana em dias alternados.

O controle do ganho de peso foi realizado semanalmente e as medidas obtidas no início e final do experimento. O comprimento $(\mathrm{cm})$ foi medido na distância entre o focinho e a base da cauda, a circunferência torácica (cm) medida logo após a pata dianteira e a abdominal aferida na parte anterior ao ante-pé. Os sítios de gorduras viscerais (omental, perirenal, epididimal, mesentérica e peritoneal) foram removidos e pesados em balança analítica após a eutanásia.

O Índice de Lee foi calculado pela relação entre a raiz quadrada de peso corporal (g) e o comprimento (cm) e o Índice de Massa Corporal (IMC) pela razão entre peso corporal $(\mathrm{g})$ e comprimento ${ }^{2}(\mathrm{~cm})^{19}$. O índice de adiposidade (IA\%) foi calculado através da relação entre a gordura corporal total e o peso corporal final multiplicado por $100^{20}$.

\section{Análise estatística}

Os dados estão expressos como média e erro padrão da média (EPM). O teste de Kolmogorov-Smirnov foi utilizado para verificar a normalidade dos dados. Após a verificação da normalidade, a análise de variância de um fator (One-way ANOVA) foi utilizada para comparação das médias com a utilização do post hoc de Tukey. Foi adotado $p<0,05$ como nível de significância. O software utilizado foi o GraphPad Prisma 5.

\section{RESULTADOS}

Ao avaliar a composição química das dietas experimentais (Tabela 1) observa-se que as três dietas diferiram significativamente entre si nos componentes cinzas, umidade, proteína e carboidrato. Na dieta bacuri, obteve-se um conteúdo lipídico superior às demais dietas, e o teor proteico da dieta whey foi de 14,13\%, próximo ao planejado (15\%), enquanto que a dieta bacuri apresentou 12,40\%, ambas inferiores ao da dieta comercial.

Os dados de consumo da dieta por animal mostram que não houve diferença significativa nos grupos alimentados com dieta comercial (G5 e G6) e os grupos que receberam a amêndoa do bacuri (G1 e G2). Verificou-se consumo significativamente inferior para os grupos que receberam fonte proteica animal (G3 e G4) (Tabela 2).
A Figura 1 revela que todos os grupos tiveram aumento de peso ao longo experimento e que a prática do exercício resistido não induziu uma alteração no peso final dos animais. Comparando-se o ganho de peso corporal dos grupos que receberam a mesma fonte proteica, nota-se que entre os grupos G1 e G2 não houve diferença estatística entre sedentários e os exercitados, o mesmo foi observado entre G3 e G4 apesar de mostrar uma tendência de menor peso no grupo exercitado; porém nos grupos G5 e G6 houve diferença indicando a eficiência dos exercícios sobre o ganho de peso. Porém, quando comparados todos os grupos, independente de fonte proteica e treinamento, G3 obteve ganho de peso significativamente maior em relação ao G1, G2 e G6.

O comprimento, índice de Lee e IMC não apresentaram diferença estatística entre os grupos ( $p>0,05)$, já as circunferências torácica e abdominal diferiram significativamente (Tabela 3), porém, não

Tabela 1. Composição química das dietas experimentais em g.100 $\mathrm{g}^{-1}$.

\begin{tabular}{c|c|c|c|c|c|c}
\hline \multirow{2}{*}{ Componentes } & \multicolumn{2}{|c|}{ Dieta Comercial } & \multicolumn{2}{c|}{ Dieta Whey protein } & \multicolumn{2}{c}{ Dieta Bacuri } \\
\cline { 2 - 8 } & BU & BS & BU & BS & BU & BS \\
\hline Umidade & $10,83 \pm 0,026^{b}$ & - & $10,11 \pm 0,071^{c}$ & - & $12,48 \pm 0,325^{a}$ & - \\
\hline Cinzas & $6,92 \pm 0,065^{a}$ & 7,76 & $2,85 \pm 0,077^{c}$ & 3,18 & $3,92 \pm 0,015^{b}$ & 4,48 \\
\hline Lipídeos & $5,06 \pm 0,034^{b}$ & 5,67 & $5,18 \pm 0,096^{b}$ & 5,76 & $9,20 \pm 0,109^{a}$ & 10,52 \\
\hline Proteínas & $20,46 \pm 0,448^{\mathrm{a}}$ & 22,94 & $14,13 \pm 0,025^{\mathrm{b}}$ & 15,72 & $12,40 \pm 0,219^{\mathrm{c}}$ & 14,17 \\
\hline Carboidratos & $22,85 \pm 0,442^{\mathrm{c}}$ & 25,63 & $29,93 \pm 0,209^{\mathrm{a}}$ & 33,28 & $25,79 \pm 0,809^{\mathrm{b}}$ & 29,47 \\
\hline VCT (kcal/100g) & 229,90 & - & 222,86 & - & 235,56 & - \\
\hline
\end{tabular}

Valores médios das determinações em triplicata \pm Erro Padrão da Media. BS: base seca; BU: base úmida; VCT: Valor calórico total. Médias seguidas por letras iguais na mesma linha não diferem entre si pelo teste de Tukey a $5 \%$ de probabilidade.

Tabela 2. Consumo médio da dieta por animal ao longo do período de intervenção.

\begin{tabular}{c|c}
\hline Grupos & Consumo da dieta por animal (g) \\
\hline G1 (Bacuri sedentário, $n=6)$ & $1202,00 \pm 29,70^{\mathrm{a}}$ \\
\hline G2 (Bacuri exercitado, $\mathrm{n}=6)$ & $1175,65 \pm 13,22^{\mathrm{ab}}$ \\
\hline G3 (Whey sedentário, $\mathrm{n}=6)$ & $1052,33 \pm 9,43^{\mathrm{bc}}$ \\
\hline $\mathrm{G} 4($ Whey exercitado, $\mathrm{n}=8)$ & $957,50 \pm 20,03^{\mathrm{c}}$ \\
\hline G5 (Comercial sedentário, $\mathrm{n}=8)$ & $1263,58 \pm 15,67^{\mathrm{a}}$ \\
\hline G6 (Comercial exercitado, $\mathrm{n}=8)$ & $1242,50 \pm 8,13^{\mathrm{a}}$ \\
\hline
\end{tabular}

Médias \pm EPM (Erro Padrão da Média). Médias seguidas por letras iguais na mesma coluna não diferem entre si pelo teste de Tukey a $5 \%$ de probabilidade.

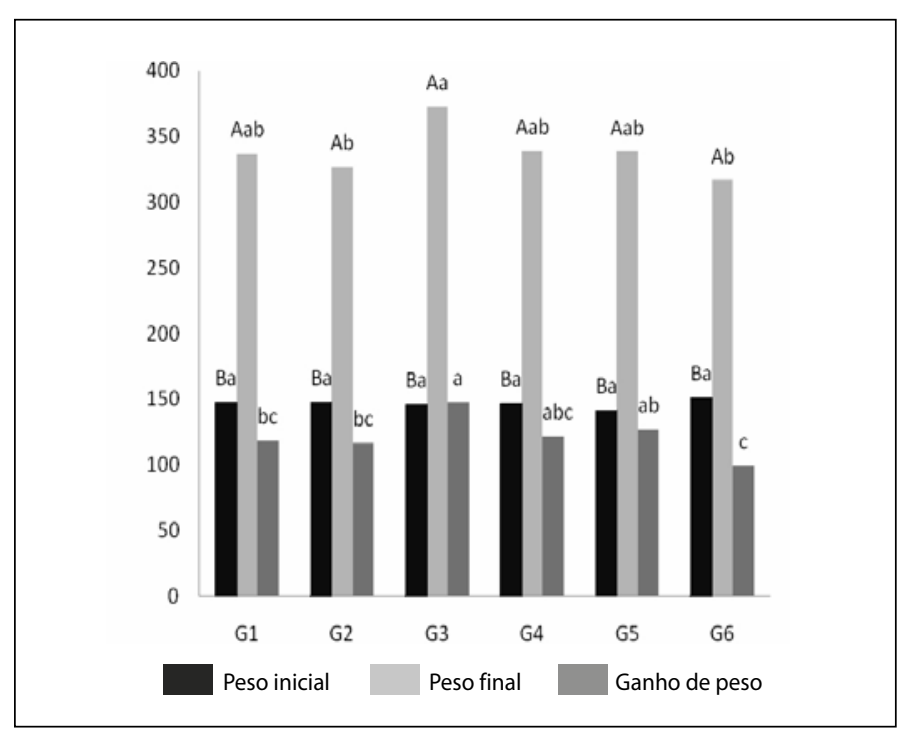

Figure 1. Peso corporal dos grupos experimentais submetidos à dieta normoproteica com bacuri e com whey (WP). G1 (bacuri sedentário); G2 (bacuri exercitado); G3 (WP sedentário); G4 (WP exercitado); G5 (controle sedentário) e G6 (controle exercitado). Letras maiúsculas comparam as médias de peso pré e pós-intervenção de cada grupo e letras minúsculas comparam os diferentes grupos entre si. Letras iguais, não diferem pelo Teste de variância ANOVA ( $p>0,05)$. 
influenciaram nos resultados da composição corporal final, como pode ser observado na Tabela 4.

Os resultados da composição corporal após oito semanas de protocolo de suplementação proteica e treinamento de força (Tabela 4) mostram que o comprimento dos animais foi significativamente maior no grupo whey sedentário em relação ao bacuri sedentário, bacuri exercitado e controle sedentário, indicando que a proteína de origem animal foi mais eficiente para promover o crescimento ${ }^{14}$.

As circunferências torácica e abdominal foram significativamente inferiores no grupo bacuri sedentário em relação aos demais grupos. Entretanto, o índice de Lee e o IMC foram superiores no bacuri sedentário em relação ao controle exercitado, os dois índices são determinantes de massa muscular e preditores de excesso de peso ${ }^{21}$.

Através da comparação das circunferências torácica e abdominal, índice de Lee e IMC nos períodos pré e pós-intervenção (Figura 2) verificou-se diferença estatística em todos esses parâmetros, os quais aumentaram após oito semanas de exercícios e suplementação sendo uma das razões, o esperado crescimento dos animais durante o estudo.

A Tabela 5 apresenta os resultados dos sítios de gordura, gordura total e índice de adiposidade. Os dados indicam que não houve diferença significativa nos sítios de gordura, refletindo também na gordura corporal total entre os grupos experimentais estudados.

Tabela 3. Avaliação da composição corporal inicial dos grupos experimentais submetidos à dieta normoproteica com bacuri e/ou whey e exercícios.

\begin{tabular}{|c|c|c|c|c|c|c|}
\hline Variáveis & G1 & G2 & G3 & G4 & G5 & G6 \\
\hline Comprimento (cm) & $13,67 \pm 0,33^{\mathrm{a}}$ & $13,83 \pm 0,31^{\mathrm{a}}$ & $14,50 \pm 0,43^{\mathrm{a}}$ & $14,17 \pm 0,31^{\mathrm{a}}$ & $14,00 \pm 0,22^{\mathrm{a}}$ & $13,75 \pm 0,16^{a}$ \\
\hline Circ. torácica $(\mathrm{cm})$ & $3,80 \pm 0,10^{a b}$ & $3,37 \pm 0,16^{b}$ & $4,28 \pm 0,13^{\mathrm{a}}$ & $3,92 \pm 0,15^{a b}$ & $4,24 \pm 0,16^{a}$ & $3,91 \pm 0,06^{a b}$ \\
\hline Circ.abdominal (cm) & $3,97 \pm 0,19^{a b}$ & $3,85 \pm 0,02^{b}$ & $4,67 \pm 0,08^{a}$ & $4,08 \pm 0,21^{a b}$ & $4,39 \pm 0,20^{a b}$ & $3,97 \pm 0,25^{a b}$ \\
\hline Índice de Lee (g/cm) & $0,63 \pm 0,023^{a}$ & $0,59 \pm 0,018^{a}$ & $0,59 \pm 0,009^{a}$ & $0,59 \pm 0,011^{\mathrm{a}}$ & $0,59 \pm 0,014^{a}$ & $0,60 \pm 0,011^{a}$ \\
\hline ÍMC $\left(\mathrm{g} / \mathrm{cm}^{2}\right)$ & $0,40 \pm 0,028^{a}$ & $0,30 \pm 0,036^{a}$ & $0,35 \pm 0,010^{\mathrm{a}}$ & $0,35 \pm 0,013^{a}$ & $0,35 \pm 0,016^{a}$ & $0,36 \pm 0,013^{a}$ \\
\hline
\end{tabular}

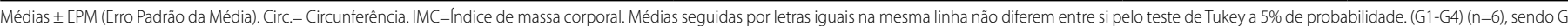
(bacuri sedentário); G2 (bacuri exercitado); G3 (whey protein sedentário); G4 (whey protein exercitado); G5(controle sedentário, $\mathrm{n=8}$ ) e G6 (controle exercitado, $\mathrm{n=8}$ ).

Tabela 4. Avaliação da composição corporal final dos grupos experimentais submetidos à dieta normoproteica com bacuri e/ou whey e exercício resistido.

\begin{tabular}{|c|c|c|c|c|c|c|}
\hline Variáveis & G1 & G2 & G3 & G4 & G5 & G6 \\
\hline Comprimento $(\mathrm{cm})$ & $22,67 \pm 0,21^{b}$ & $22,67 \pm 0,21^{b}$ & $24,33 \pm 0,21^{\mathrm{a}}$ & $23,17 \pm 0,31^{a b}$ & $22,57 \pm 0,43^{b}$ & $23,25 \pm 0,25^{a b}$ \\
\hline Circ. torácica (cm) & $11,83 \pm 1,19^{b}$ & $14,70 \pm 0,32^{\mathrm{a}}$ & $16,05 \pm 0,22^{\mathrm{a}}$ & $15,33 \pm 0,25^{a}$ & $14,86 \pm 0,24^{\mathrm{a}}$ & $14,44 \pm 0,24^{a}$ \\
\hline Circ. abdominal (cm) & $14,15 \pm 0,99^{b}$ & $17,47 \pm 0,59^{a}$ & $16,70 \pm 0,14^{\mathrm{a}}$ & $16,92 \pm 0,20^{\mathrm{a}}$ & $16,64 \pm 0,42^{\mathrm{a}}$ & $16,37 \pm 0,28^{a}$ \\
\hline Índice de Lee (g/cm) & $0,803 \pm 0,018^{a}$ & $0,782 \pm 0,014^{\mathrm{ab}}$ & $0,782 \pm 0,003^{a b}$ & $0,781 \pm 0,010^{\mathrm{ab}}$ & $0,798 \pm 0,013^{a b}$ & $0,752 \pm 0,01^{b}$ \\
\hline ÍMC $\left(\mathrm{g} / \mathrm{cm}^{2}\right)$ & $0,65 \pm 0,028^{a}$ & $0,61 \pm 0,022^{a b}$ & $0,61 \pm 0,005^{\mathrm{ab}}$ & $0,61 \pm 0,015^{a b}$ & $0,64 \pm 0,021^{a b}$ & $0,57 \pm 0,011^{b}$ \\
\hline
\end{tabular}

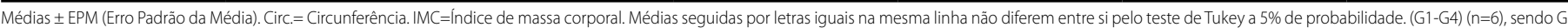
(bacuri sedentário); G2 (bacuri exercitado); G3 (whey protein sedentário); G4 (whey protein exercitado); G5 (controle sedentário, n=8) e G6 (controle exercitado, n=8).

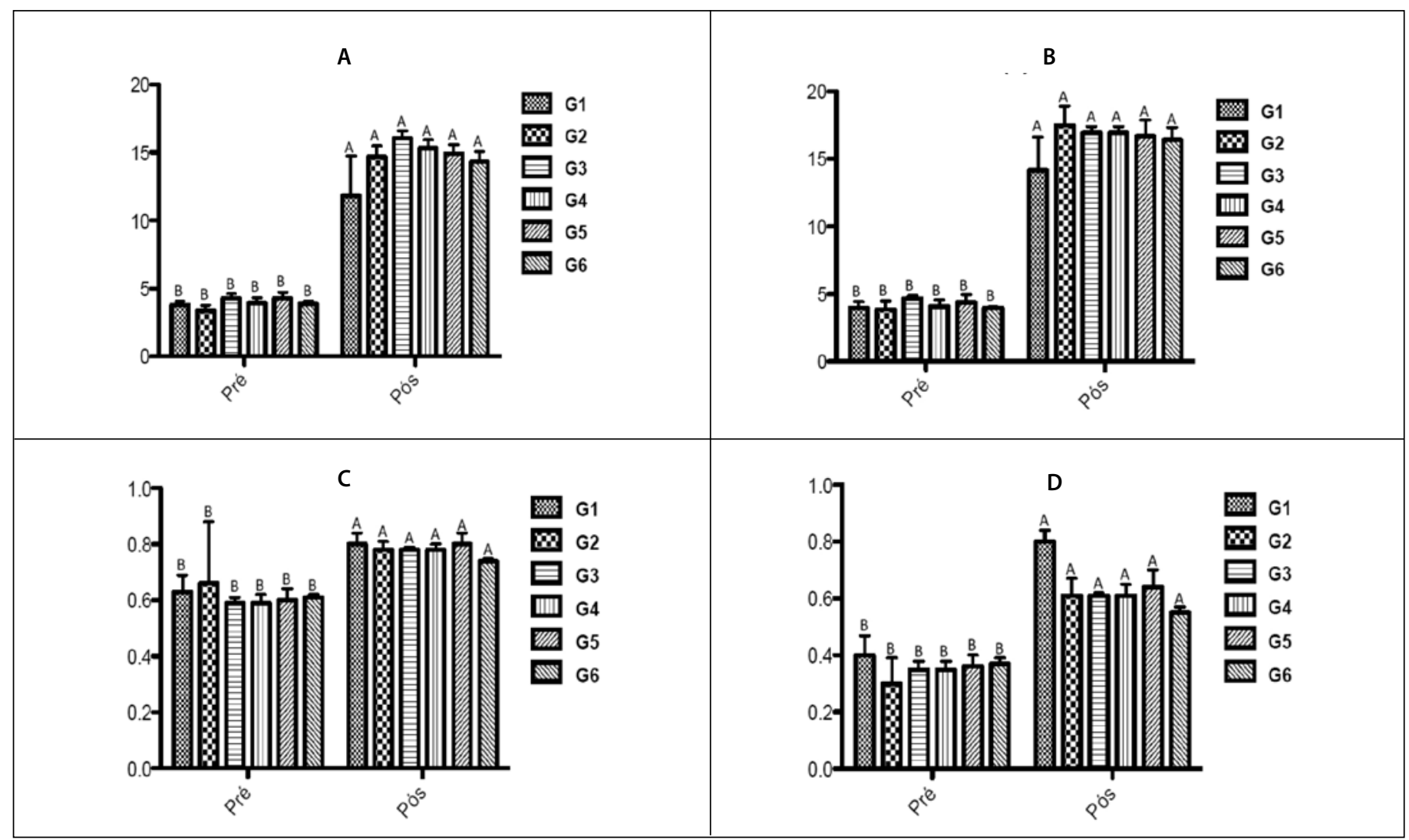

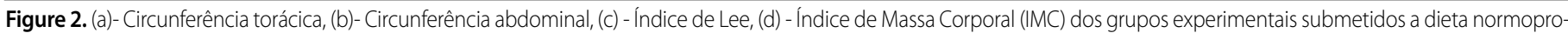

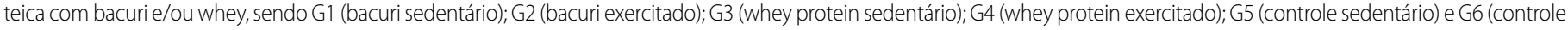
exercitado). Letras maiúsculas comparam as médias pré e pós-intervenção de cada grupo. Letras diferentes diferem entre si pelo Teste de variância ANOVA ( $p=0,0001$ ). 
Tabela 5. Peso dos sítios de gordura corporal dos grupos experimentais submetidos à dieta normoproteica com bacuri e/ou whey e exercício resistido.

\begin{tabular}{|c|c|c|c|c|c|c|}
\hline Sítios de Gordura (g) & G1 & G2 & G3 & G4 & G5 & G6 \\
\hline Peritoneal & $3,95 \pm 0,59^{a}$ & $4,33 \pm 0,44^{\mathrm{a}}$ & $4,89 \pm 0,37^{a}$ & $5,31 \pm 1,12^{\mathrm{a}}$ & $4,32 \pm 0,72^{\mathrm{a}}$ & $3,07 \pm 0,36^{a}$ \\
\hline Perirenal & $1,11 \pm 0,18^{a}$ & $0,95 \pm 0,09^{a}$ & $1,28 \pm 0,07^{a}$ & $1,34 \pm 0,14^{\mathrm{a}}$ & $1,32 \pm 0,21^{\mathrm{a}}$ & $0,95 \pm 0,11^{\mathrm{a}}$ \\
\hline Epididimal & $5,46 \pm 0,47^{a}$ & $4,85 \pm 0,29^{a}$ & $6,37 \pm 0,42^{a}$ & $6,45 \pm 0,58^{a}$ & $5,20 \pm 0,75^{a}$ & $4,38 \pm 0,30^{a}$ \\
\hline Mesentérica & $3,63 \pm 0,29^{a}$ & $4,28 \pm 0,17^{a}$ & $4,35 \pm 0,37^{a}$ & $4,59 \pm 0,65^{a}$ & $3,94 \pm 0,41^{\mathrm{a}}$ & $3,32 \pm 0,16^{a}$ \\
\hline Omental & $0,72 \pm 0,08^{a}$ & $0,37 \pm 0,17^{a}$ & $0,56 \pm 0,14^{a}$ & $0,41 \pm 0,09^{a}$ & $0,82 \pm 0,11^{a}$ & $0,58 \pm 0,07^{a}$ \\
\hline Gordura total & $14,86 \pm 1,49^{a}$ & $14,78 \pm 0,91^{\mathrm{a}}$ & $17,45 \pm 1,08^{a}$ & $18,10 \pm 2,16^{a}$ & $15,59 \pm 2,09^{a}$ & $12,30 \pm 0,93^{\mathrm{a}}$ \\
\hline $\mathrm{IA} \%{ }^{1}$ & $4,36 \pm 0,33^{a}$ & $4,54 \pm 0,25^{a}$ & $4,67 \pm 0,24^{a}$ & $5,28 \pm 0,46^{a}$ & $4,59 \pm 0,58^{a}$ & $3,89 \pm 0,30^{a}$ \\
\hline
\end{tabular}

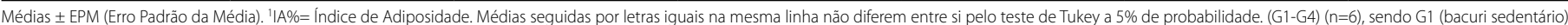
G2 (bacuri exercitado); G3 (WP sedentário); G4 (WP exercitado); G5 (controle sedentário, n=8) e G6 (controle exercitado, $n=8$ ).

\section{DISCUSSÃO}

Embora os valores da composição das dietas tenham se mostrado diferentes estatisticamente com relação aos macronutrientes (lipídeos, proteínas e carboidratos), os resultados de VCT das mesmas foram próximos. A dieta comercial utilizada apresentou maior teor de proteínas $(20,46 / 100 g)$, porém inferior ao declarado pelo fabricante em sua embalagem (22,2g de proteína bruta/100g).

O menor consumo observado em animais dos grupos alimentados com dietas preparadas com whey protein pode indicar uma maior saciedade, pois segundo Melo e Bordonal22 essa é uma característica proporcionada por concentrados proteicos. O whey protein tem sido reconhecido pela sua capacidade de regular a glicose no sangue e manter o peso corporal através do aumento da saciedade e da consequente redução da ingestão de alimentos; assim como o rápido aumento de aminoácidos que estimulam hormônios gastrointestinais, como a colecistoquinina (CKK), e também pela presença de glicomacropeptídeos (GMP) que influenciam as funções gastrointestinais pela inibição da secreção gástrica ${ }^{23}$.

O efeito da proteína do champignon do Brasil (Agaricus brasiliensis) foi pesquisado em ratos, comparando com um grupo controle (caseína) e outro grupo de baixo teor proteico, verificou-se menor peso no grupo alimentado com proteína vegetal quando comparado ao controle ${ }^{24}$. No presente estudo os grupos alimentados com a proteína vegetal também tiverem menor ganho de peso, assim como o grupo controle exercitado que teve seu ganho reduzido provavelmente pelo efeito do exercício resistido.

Em relação ao treinamento resistido, estudo semelhante avaliou as reservas glicogênicas de músculos e parâmetros indicadores de ajustes metabólicos em relação ao protocolo de treinamento utilizando animais controle (sedentários) e experimental (exercitados), os quais também foram submetidos ao treinamento resistido com escada, e o grupo exercitado obteve menor peso em relação ao controle sedentário ${ }^{25}$. Embora os animais tenham apresentado aumento dos índices de Lee e de massa corporal em função do crescimento, esperava-se que nos grupos submetidos ao treinamento resistido estes aumentos fossem reduzidos quando comparados aos grupos sedentários. Porém, esses resultados também podem ser atribuídos ao treinamento resistido, que quando executado corretamente e continuamente pode gerar adaptações neurais e musculares ${ }^{26}$.

Estudo com ratas adultas citam que índice de Lee maior que 0,3 pode ser usado como indicador do excesso de gordura corporal ${ }^{27}$. Porém, no presente estudo, todos os grupos iniciaram o protocolo de treinamento e suplementação proteica com valores próximos a 0,6 aumentando para 0,8. Para Angéloco et al. ${ }^{28}$, o IMC pode estimar de forma confiável a gordura corporal em rato, sendo diretamente proporcional ao seu crescimento, já o índice de Lee é considerado menos sensível, pois animais com elevada quantidade de massa muscular podem apresentar elevado índice de Lee mesmo que a gordura corporal não seja excessiva ${ }^{19-21}$.
No entanto, nessa pesquisa os resultados não evidenciaram grandes diferenças nesses parâmetros e não refletiram alterações substanciais da gordura total entre os grupos avaliados.

Pesquisa realizada com ratos mostrou que valores de IMC aumentaram até 90 dias de idade $\left(0,45\right.$ para 0,68 $\left.\mathrm{g} / \mathrm{cm}^{2}\right)$, mantendo-se constantes até 150 dias $^{19}$. No presente trabalho, os valores variaram entre 0,30 a $0,40 \mathrm{~g} / \mathrm{cm}^{2}$ (idade de 43 dias) e após oito semanas de treinamento anaeróbico resistido em escadas (idade de100 dias) variaram de 0,57 a 0,65 g/ $\mathrm{cm}^{2}$, estando, portanto, dentro dos parâmetros de normalidade para ratos Wistar.

Nascimento et al. ${ }^{20}$ induziram a ingestão de dieta rica em gordura durante 30 semanas e compararam com um grupo controle de peso normal, ambos sem exercícios, e verificaram que o índice de adiposidade (\%) variou de 4,28 \pm 1,65\% (grupo controle) a 5,96 \pm 1,54\% (grupo de ratos obesos). Na presente pesquisa não houve diferença significativa no índice de adiposidade entre os grupos experimentais, podendo-se apenas observar uma tendência de valores maiores para os grupos que receberam whey protein em relação aos grupos que receberam bacuri, mesmo essa dieta contendo maior teor lipídico.

Embora fosse esperado que os grupos de animais submetidos ao treinamento resistido apresentassem menor aumento dos índices avaliados em comparação aos sedentários, isto não ocorreu, possibilitando novos caminhos no estudo tanto da suplementação quanto do treinamento resistido, sugerindo novas formas de suplementação (quantidade, frequência, fontes) como na manipulação do treinamento (intensidade, volume, frequência).

\section{CONCLUSÕES}

Conclui-se que a proteína da amêndoa do bacuri é de boa qualidade quando comparada à proteína animal do whey protein, havendo possibilidade de recomendação para o seu uso na elaboração de suplementos nutricionais, como fonte vegetal alternativa e de baixo custo. Os animais que receberam bacuri consumiram quantidade superior de dieta, porém, tiveram menor peso final; não diferiram nos índices de Lee e IMC, nos sítios de gordura, gordura total e índice de adiposidade em relação aos grupos alimentados com whey, apresentando valores inferiores nas circunferências torácica e abdominal.

Verificou-se a necessidade em dar continuidade aos estudos avaliando o tempo de duração e a frequência do treinamento resistido.

\section{AGRADECIMENTOS}

Os autores agradecem a Coordenação de Aperfeiçoamento de Pessoal de Nível Superior (CAPES) e a Fundação de Apoio ao Desenvolvimento do Ensino, Ciência e Tecnologia do Estado de Mato Grosso do Sul (FUNDECT) pelo apoio financeiro.

Todos os autores declararam não haver qualquer potencial conflito de interesses referente a este artigo. 
CONTRIBUIÇÕES DOS AUTORES: Cada autor contribuiu individual e significativamente para o desenvolvimento do manuscrito. MLMR (0000-0001-6587-4962)* e GCGR (0000-0001-6575-1815)* participaram na execução do projeto e redação. WRGS (0000-0002-3027-5422)* contribuiu na execução laboratorial e atividades do biotério. PAH (0000-0003-1115-4083)* contribuiu na coordenação, redação e revisão. MILR (0000-0002-3664-2166)* contribuiu na execução, redação e revisão. JAA (0000-00023409-8005)* contribuiu com a revisão e análise estatística dos dados. FLFZS (0000-0002-0096-3697)* contribuiu na concepção, análise de dados e revisão *ORCID (Open Researcher and Contributor ID).

\section{REFERÊNCIAS}

1. Piaia CC, Rocha FY, Vale GDBFG. Nutrição no exercício físico e controle de peso corporal. Rev Bras Nutr Esportiva. 2007;1(4):40-8.

2. Nicastro H, Dattilo M, Santos TR, Padilha HVG, Zimberg I Z, Crispim CA, et al. Aplicação da Escala de Conhecimento Nutricional em Atletas Profissionais e Amadores de Atletismo, Rev Bras Med Esporte. 2008;14(3):205-8.

3. Hernandez AJ, Nahas RM. Modificações dietéticas, reposição hídrica, suplementos alimentares e drogas: comprovação de ação ergogênica e potenciais riscos para a saúde. Rev Bras Med Esporte. 2009;15(2):1-12.

4. Alves SCR, Navarro F. O uso de suplementos alimentares por frequentadores de academia de Potim-SP. Rev Bras Nutr Esportiva. 2010;4(20):139-46.

5. Grahl G, Noamann JT, Nunes RH, Flores LJF. Efeitos do treinamento resistido na redução do percentual de gordura corporal em adultos: uma revisão de literatura. Cad Ed Fis Esporte. 2013;11(2):69-77.

6. Souza TMF, Cesar MC, Borin JP, Gonelli PRG, Simões RA, Montebelo MIL. Efeitos do treinamento de resistência de força com alto número de repetições no consumo máximo de oxigênio e limiar ventilatório de mulheres. Rev Bras Med Esporte. 2008;14(6):513-7.

7. Brito CJ, Mendes EL, Ferreira AP, Paula SO, Nóbrega OT, Córdova C. Impacto do treinamento resistido na força e hipertrofia muscular em HIV-soropositivos. Motriz: Rev Ed Fis. 2013;19(2):313-24.

8. Vargas CS, Fernandes RH, Lupion R. Prevalência de uso de suplementos nutricionais em praticantes de atividade física de diferentes modalidades. Rev Bras Nutr Esportiva. 2015;9(52):343-9.

9. SgarbieriVC Propriedades fisiológicas-funcionais das proteínas do soro do leite. Rev Nutr. 2004;17(4):397-409.

10. Fischborn SC A influência do tempo de ingestão da suplementação de whey protein em relação à atividade física. Rev Bras Nutr Esportiva. 2009;3(14):132-43.

11. Lima e Silva MCB, Hiane PA, Braga Neto JA, Macedo MLR. Proteins of Bacuri almonds - Nutritional value and in vivo digestibility. Food Sci Technol. 2014;34(1):55-61.

12. World Health Organization. Food and Agriculture Organization. Protein and amino acid requirements in human nutrition. Geneva: WHO; 2007.

13. Ziegler FLF. Avaliação do efeito da suplementação com proteínas lácteas sobre pacientes com leucemia mieloide aguda (LMA), na mucosite induzida por quimioterápicos e em células leucêmicas [tese]. Campinas, SP: Universidade Estadual de Campinas; 2010.

14. Ziegler FLF, Castro G, Moreno YF, Oya V, Vilela MMS, Sgarbieri VC. Partial chemical and functional characterization of milk whey products obtained by different processes. Ciênc Tecnol Aliment. 2012;32(1):56-64.
15. Instituto Adolfo Lutz. Métodos físico-químicos para análise de alimentos. São Paulo: Instituto Adolfo Lutz; 2008. 16. Horwtz W. Official methods of analysis. 15th ed. Washington, DC: Association of official analytical chemists; 1990.

17. Reeves PG, Nielsen FH, Fahey JGC. AIN-93. Purified diets for laboratory rodents: final report of the American Institute of Nutrition Ad Hoc Writing Committee on the formulation of the AIN-76A rodent diet. J Nutr. 1993;123(11):1939-51.

18. Hornberger TA, Farrar RP. Physiological hypertrophy of the FHL muscle following 8 weeks of progressive resistance exercise in the rat. Can J Appl Physiol. 2004;29(1):16-31.

19. Novelli ELB, DinizYS, Galhardi CM, Ebaid GMX, Rodrigues HG, Mani F, et al. Anthropometrical parameters and markers of obesity in rats. Lab Anim. 2007;41(1):111-9.

20. Nascimento TB, Baptista RFF, Pereira PC, Campos DHS, Leopoldo AS, Leopoldo APL, et al. Alterações vasculares em ratos obesos por dieta rica em gordura: papel da via L-arginina/NO endotelial. Arq Bras Cardiol. 2011;97(1):40-5.

21. Nery CS, Pinheiro IL, Muniz GS, Vasconcelos DAA, França SP, Nascimento E. Medidas murinométricas e eficiência alimentar em ratos provenientes de ninhadas reduzidas na lactação e submetidos ou não ao exercício de natação. Rev Bras Med Esporte. 2011;17(1):49-55.

22. Melo FF, Bordonal VC. Relação do consumo da whey protein isolada e como coadjuvante na atividade física. Rev Bras Nutr Esportiva. 2009;3(17):478-87.

23. Terada LC, Godoi MR, Silva TCV, Monteiro TL. Efeitos metabólicos da suplementação do Whey Protein em praticantes de exercícios com pesos. Rev Bras Nutr Esportiva. 2009;3(16):295-304.

24. Henriques GS, Simeone MLF, Amazonas MALA. Avaliação in vivo da qualidade proteica do champignon do Brasil (Agaricus brasiliensis Wasser). Rev Nutr. 2008;21(5):535-43.

25. Rodrigues MD, Borin SH, Silva CA. Relações metabólicas em ratos sob o treinamento anaeróbio em escada. Rev Bras Ciênc Esporte. 2016;39(1):63-7.

26. Bacurau FR, Navarro F, Uchida CM. Hipertrofia hiperplasia. 3a ed. São Paulo, SP: Phorte; 2009

27. Bernardis LL, Patterson BD. Correlation between'Lee index'and carcass fat content in weanlingand adult female rats with hypothalamiclesions. J Endocrinol. 1968;40:527-28.

28. Angéloco LRN, Deminice R, Leme IA, Lataro RC, Jordão AA. Bioeletrical impedance analysis and anthopometry for the determination of body composition in rats: effects of high-fatand high-sucrose diets. Rev Nutr. 2012;25(3):331-39. 